\title{
Abductor pollicis longus muscle - is it a new variant of the extensor forearm and thenar eminence or a well-known variation?
}

\author{
G.P. Georgiev \\ Department of Orthopaedics and Traumatology, University Hospital Queen Giovanna - ISUL, \\ Medical University of Sofia, Bulgaria
}

[Received: 23 March 2020; Accepted: 1 April 2020]

I read with interest the article by Mishall et al. [4] on a supposedly previously unreported variation: "Novel, bilateral, two-bellied muscles span the extensor forearm, thenar eminence to insert on the proximal phalanx of the thumb: clinical and embryological significance." The case details similar bilateral, additional muscles that had proximal separate and distinct bellies from the abductor pollicis longus muscle (APL) and ran parallel to it. The distal bellies of the novel muscles ran near the abductor pollicis brevis muscles (APB) and attached to the proximal phalanges of the thumbs. According to Mishall et al. [4], knowledge on such variations might explain complications after surgery and a recurrence of inflammatory diseases and dysfunction of the hand.

However, I do not agree with the author's claims that this is a novel report. In 1875, Macalister [3] described this variation and more recently [2]. Moreover, variations of the APL are widely known to anatomists and surgeons e.g., Bergman et al. [1] - Illustrated Encyclopedia of Human Anatomic Variations. Many times during my anatomical dissections, I've easily divided the so called "additional" novel muscle as reported by from Mishall et al. [4]. Additionally, to understand if the distal bellies of the novel muscles were truly 'additional' or only part of the typical APB, the authors made measurements on the cadaver of interest as well as 11 additional male cadavers. This methodology is unacceptable, and I do not understand why the authors decided to use it to find their novel variation, which again, is well known. As I pointed out, the novel belly of the APB can easily be dissected out.
In conclusion, this case highlights the need for better control from editors and reviewers for such reports and should serve as a warning to future authors who want to describe "novel" variations. Although the authors state they carried out a "thorough search of the literature", I advise the present and future authors to first more thoroughly check older literature and if possible, literature in non-native languages as most of the time, previous reports will be found. Quick searches using search engines such as PubMed, which are limited in their scope, are not sufficient for detailed anatomical studies many of which were published one or two hundred years ago.

\section{REFERENCES}

1. Bergman RA, Afifi AK, Miyauchi R (2017) Title of subordinate document. In: Illustrated Encyclopedia of Human Anatomic Variations. Available via DIALOG. http://www. anatomyatlases.org/AnatomicVariants/MuscularSystem/ Text/E/25Extensor.shtml (Accessed 19 March 2020).

2. Iliev A, Georgiev GP, Kotov G, et al. The abductor pollicis longus tendon as grafting material for reconstructive surgery of the hand. Acta Morphol Anthropol. 2017; 24(1-2): 68-73.

3. Macalister A. Additional observations on muscular anomalies in human anatomy (third series), with a catalogue of the principal muscular variations hitherto published. Trans Roy Irish Acad. 1875; 25: 1-130.

4. Mishall PL, Marsh AN, Perez D, et al. Novel, bilateral, two-bellied muscles span the extensor forearm, thenar eminence to insert on the proximal phalanx of the thumb: clinical and embryological significance. Folia Morphol. 2020; 79(1): 182-187, doi: 10.5603/FM.a2019.0067, indexed in Pubmed: 31169299. 